\title{
Growth, Yield and Quality Attributes of Mango Cultivars under the Sultanate of Oman Conditions
}

\author{
Kh. T. Al-Busaidi ${ }^{*}$, M. H. Al-Jabri ${ }^{*}$, P. Vis wanath*, K.H. \\ Al-Jaffry $^{*}$ and B. S. Al-Lawati** \\ *Fruit Research Section, Plant Production Research Centre, \\ Directorate GeneralofAgriculture andLivestock Research, P.O. \\ Box 50 postal code 121, Seeb, and ${ }^{* *}$ Directorate general of \\ Agricultural Development, Ministry of Agriculture and Fisheries, \\ P.O. Box 467 postal code 100, Alkhowair, Sultanate of Oman.
}

\begin{abstract}
A DAPTATION of mango varieties to local environmental $A$ conditions is one of the most important alternatives for sustainability of mango cultivation in Oman, taking advantage of the high genetic diversity. Seventeen mono-embryonic Indian mango varieties grafted on local Omani rootstock were studied with respect to growth, yield and quality attributes. The results revealed that there was a variation between varieties with respect to their vegetative growth parameters which had large variation viz. 3.10- $7.5 \mathrm{~cm}$ for tree height, 3-7 m vegetative growth spreading, $45-98 \mathrm{~cm}$ for trunk girth and 15.09-195.06 $\mathrm{m}^{3}$ tree vegetative canopy volume. These data identified the growth habit of each variety in the sense that Ross variety $(3.10 \mathrm{~m})$ was dwarf compared to tall varieties of Immampasand, Zafran, and Pairi (7.50, 6.50 and $6 \mathrm{~m}$, respectively) and had vigorous growth (195.06, 104.76 and $101.89 \mathrm{~m}^{3}$, respectively). The results showed that average fruit weight ranged between 200-1200 g/fruit, where Tanneru variety gave the highest fruit weight (1200 g/fruit), while Chambtan, Ross, Pairi, Baramasi and Alphonso were the lowest (200 g/fruit). Average fruit number varied from 77- 497 fruit/tree) and Neelum variety was the highest (497 fruit/tree) and Baramasi was the least ( 977 fruit /tree). Ross trees were more efficient in production $\left(16 \mathrm{~kg} / \mathrm{m}^{3}\right)$, followed by Deshari $(15.09$ $\mathrm{kg} / \mathrm{m}^{3}$ ). Safeda Mulgoa distinct to other varieties in total soluble solids $(21 \%)$. Tested varieties were classified into four maturity periods groups viz early, mid-early, medium and late. There was no significant difference between groups with respect to growth parameters. Numerically group of mid- early varieties were shorter and less vigorous in growth and more productive than other groups. Tree yield efficiency was negatively correlated with tree canopy volume $(\mathrm{r}=-0.561, \mathrm{p} \leq 0.05)$. It was concluded that adaptation of mango genetic diversity would be very efficient strategy to develop sustainable mango cultivations under the Omani conditions.
\end{abstract}

Keywords: Chemical characters, Varieties, Growth paramaters, Yield components.

Mango (Mangifera indica L.) which belongs to the dicotyledonous family Anacardiaceae, is one of the most important tropical and subtropical fruit crops in 
the world. Globally, it is fifth-ranked in production among major fruit crops, where 100 countries are recorded as mango producing countries in current FAO statistics. Mango was introduced to the Sultanate of Oman since hundred years, mainly from the Indian subcontinent and East Africa. Countrywide, it is fourth most important fruit crop after date palm (Phoenix dactylifera L.), banana (Musa spp) and lime (Citrus aurantifolia) in terms of area and production (148,514 hectare and 8637 ton, respectively, MAF 2013). Shortage and low quality of water are the main challenges regarding expansion in the cultivation of mango in the Sultanate, where the annual precipitation average is $100 \mathrm{~mm}$. Mango genetic diversity is a key issue for sustainability cultivation of this cropas they have genetic characters enable to withstand local environmental conditions. Many researchers (Kaur et al., 2014, Naqvi et al., 2014, Okoth et al., 2013, Usman et al., 2011, Jilani et al., 2010, Rajan et al., 2001, Akhtar et al., 2009, Singh \& Kanpure, 2006 and Chanana et al., 2005) have followed the same path in terms of the use of genetic diversity for the development of mango cultivation in their areas. This investigation aims to evaluate the performance of mango varieties grafted on local Omani rootstock in terms of growth, yield and quality attributes under Omani conditions.

\section{Materials and Methods}

Seventeen mono-embryonic Indian mango varieties namely, Allumpur Baneshan, Alfonso, Banglora, Baneshan, Baramasi, Cherukurasam, Dasheri, Imam Pasand, Langra, Mulgoa, Neelum, Pairi, Ross, Safed Mulgoa, Tenneru, Zafran and Chambatan grafted on local Omani mango monoemberyonic rootstock were planted and evaluated at Agricultural Research Farm, Rumais which had sandy loam soil. Bubbler irrigation system was used to irrigate the trees. The spacing between the trees was $7 \mathrm{~m} \times 7 \mathrm{~m}$. Fertilization and protection and other cultural practices were used according to the research centre recommendation. Data of growth parameters (tree height $(\mathrm{m})$, tree spreading $(\mathrm{m})(\mathrm{E}-\mathrm{W}, \mathrm{N}-\mathrm{S})$, trunk girth $(\mathrm{cm})$ and tree canopy volume $\left(\mathrm{m}^{3}\right)$ from ten years old trees were measured. Tree height was measured by clinometers instrument. Matric tape was used to determine tree spreading and trunk girth. For spreading, two observations on each of east west and north south sides of selected trees were measured. Tree canopy volume was calculated according to Zekri (1996). Yield components (fruit weight (g), fruit No./ tree , yield $(\mathrm{kg})$ and tree yield efficiency $\left(\mathrm{kg} / \mathrm{m}^{3}\right)$, flowering and maturity periods were recorded by taking representative random five fruits from each five trees per variety at harvesting date. Tree yield efficiency was calculated by dividing tree yield $(\mathrm{kg})$ on the tree canopy volume $\left(\mathrm{m}^{3}\right)$. Total soluble solids (TSS $\%$ ) was measured using digital refractometer (model optic ivymen system, ctra. Nz km 585.1 Abrera (Barceluna), Spain). All data were recorded and statistically analyzed by using GenStat version 11 and SPSS statistics 17.0.

\section{Results and Dicussion}

\section{Vegetative growth behaviour}

Mango tree growth habit, viz. tree height, tree spreading, trunk girth and tree canopy volume is one of the most important issues that suppose to be taken in consideration in such studies as reported in the previous studies (Kaur et al., 2014,

Egypt. J. Hort. Vol. 42, No. 1 (2015) 
Singh \& Kanpur, 2006, Chaman et al., 2005, Rajan et al., 2001 and Abutiate, 1987). These characters are important in the case of the expansion of the cultivation of any variety, in the sense plant density per unit area. The results of this investigation showed a wide range of variability between mango genotypes with respect to tree growth characters (Table 1). This variation in tree growth habit was also reprted by Kaur et al. (2014), Chaman et al. (2005) and Rajan et al. (2001) who evaluated mango variaties under different Indian regions. Average tree hight ranged between $3.10-7.5 \mathrm{~cm}$, where Ross variety recorded the lowest height $(3.10 \mathrm{~m})$ followed by Dashehari $(3.80 \mathrm{~m})$, while Imampas and was the highest $(7.50$ $\mathrm{m})$. Same varieties recorded the same trend with respect to the tree spread (West East and North-South) which ranged between 3-7.10 and 3.0-7.0 m, respectively as well as trunk girth and tree canopy volume $\left(45-98 \mathrm{~cm}\right.$ and $15.09-195.06 \mathrm{~m}^{3}$, respectively). Our results differs from the results of Chanana et al. (2005) who found that Dashehari and ILangra varieties have big tree canopy volume (186.33 and $311.38 \mathrm{~m}^{3}$, respectively) under Punjab region in India, while Alphonso variety recorded canopy volume $\left(58.98 \mathrm{~m}^{3}\right)$ close to that under Omani conditions.

TABLE 1. Growth characters of different mango varieties grown under the Sultanate of Oman conditions.

\begin{tabular}{|c|c|c|c|c|c|}
\hline Varieties & $\begin{array}{c}\text { Tree height } \\
(\mathbf{m})\end{array}$ & $\begin{array}{c}\text { E-W spread } \\
(\mathbf{m})\end{array}$ & $\begin{array}{c}\text { N-S spread } \\
(\mathbf{m})\end{array}$ & $\begin{array}{c}\text { Trunk girth } \\
(\mathbf{m})\end{array}$ & $\begin{array}{c}\text { Canopy } \\
\left.\text { volume } \mathbf{( m}^{3}\right)\end{array}$ \\
\hline Allumpur Baneshan & 4.50 & 4.80 & 4.70 & 63.00 & 53.13 \\
\hline AlPhonso & 5.70 & 4.80 & 4.80 & 64.50 & 68.72 \\
\hline Banglora & 4.60 & 4.70 & 4.70 & 62.00 & 53.17 \\
\hline Baneshan & 4.10 & 3.90 & 4.00 & 49.40 & 33.47 \\
\hline Baramasi & 4.50 & 3.50 & 3.60 & 61.00 & 29.67 \\
\hline Cherukurasam & 5.40 & 4.90 & 4.80 & 76.00 & 66.46 \\
\hline Dashehari & 3.80 & 4.00 & 4.00 & 49.50 & 31.82 \\
\hline Imampasand & 7.50 & 7.10 & 7.00 & 98.00 & 195.06 \\
\hline Langra & 5.00 & 5.60 & 4.60 & 63.00 & 67.40 \\
\hline Mulgoa & 4.50 & 4.50 & 4.30 & 60.00 & 45.57 \\
\hline Neelum & 5.60 & 5.80 & 4.60 & 70.00 & 78.19 \\
\hline Pairi & 6.10 & 5.60 & 5.70 & 77.00 & 101.89 \\
\hline Ross & 3.10 & 3.00 & 3.10 & 45.00 & 15.09 \\
\hline Safeda Mulgoa & 4.90 & 4.90 & 4.40 & 65.20 & 55.28 \\
\hline Tenneru & 5.00 & 4.60 & 4.30 & 54.00 & 51.75 \\
\hline Zafran & 6.50 & 5.60 & 5.50 & 75.00 & 104.76 \\
\hline Chambatan & 5.50 & 5.40 & 5.30 & 80.00 & 82.37 \\
\hline Mean & 5.08 & 4.86 & 4.67 & 65.45 & 66.69 \\
\hline SE \pm & 1.24 & 1.19 & 1.14 & 15.96 & 16.27 \\
\hline Range & $3.10-7.50$ & $3-7$ & $3.10-7$ & $45-98$ & $15.09-19.5$ \\
\hline & & & & &
\end{tabular}

Kaur et al. (2014) found tree height of Alphonso $12.43 \mathrm{~m}$. Assuming that there was no mistakes regarding variety names, theses differences may be 
attributed to the variation in cultural practices between locatins and also to the rootstock. The compilation of varieties according to the maturity periods made it clear that all varieties were under four groups, early, mid-early, medium and late (Table 2). Tenneru, Zafran and Pairi are early mature (April-May), Ross and Banglora are mid-early mature (Mid of May to June), Neelm variety is late August-September) while the rest varieties are medium mature.

As compared with other groups, all varieties in mid-Early group are considered as dwarf varieties having short tree height, $3.9 \mathrm{~m}$ and $34.1 \mathrm{~m}^{3}$ in canopy volume while early varieties were more vigorous, viz.5.9 m tree height and $86.1 \mathrm{~m}^{3}$ for canopy volume follwed by late variety which gave $5.6 \mathrm{~m}$ tree height and $80 \mathrm{~m}^{3}$ canopy volume. This confirms the importance of mango genetic diveristy in extending fruiting season for mango and consequently contributing in sustainability cultivation of this crop.

TABLE 2. Growth characters of mango varieties according to maturity periods.

\begin{tabular}{|c|c|c|c|c|c|}
\hline \multirow{2}{*}{$\begin{array}{c}\text { Maturity } \\
\text { period }\end{array}$} & \multirow{2}{*}{$\begin{array}{c}\text { Tree height } \\
(\mathbf{m})\end{array}$} & \multirow{2}{*}{$\begin{array}{c}\text { Trunk girth } \\
(\mathbf{c m})\end{array}$} & \multicolumn{2}{|c|}{ Tree Spreading } & \multirow{2}{*}{$\begin{array}{c}\text { Canopy } \\
\text { volume } \\
\left(\mathbf{m}^{\mathbf{3}}\right)\end{array}$} \\
\hline Early & $5.9 \pm 0.449$ & $68.7 \pm 7.356$ & $5.2 \pm 0.437$ & $5.3 \pm 0.333$ & $86.1 \pm 17.212$ \\
\hline Mid-Early & $3.9 \pm 0.750$ & $53.5 \pm 8.500$ & $3.9 \pm 0.800$ & $3.9 \pm 0.850$ & $34.1 \pm 19.04$ \\
\hline Medium & $5.2 \pm 0.432$ & $66.2 \pm 5.683$ & $4.8 \pm 0.376$ & $5.1 \pm 0.386$ & $74.1 \pm 20.681$ \\
\hline Late & $5.6 \pm 0.050$ & $75.0 \pm 5.000$ & $5.0 \pm 0.350$ & $5.6 \pm .0200$ & $80.3 \pm 2.093$ \\
\hline
\end{tabular}

Flowering, maturity, yield and quality behaviour

It was observed that flowering initiatiated from December to February in most varieties (Fig.1). Early varieties like Tanneru, Zafran and Pairi flowerd in early December while the medium varieties (Safeda Mulgoa, Beneshan, Alphonso, Langra, Mulgoa) by the end of December to middle of January. Late varieties (Neelum and Chambatan) flowered during middle of January to end of February. Most varieties remained in maturity during the middle of May till end of July and were categorized as medium (Fig. 2). The varieties fruiting during August and September are catogrized as late varieties (Neelum and Chambatan) and those fruiting during middle of April to middle of May were grouped as early varieties (Tenneur, Zafran, Pairi). Varieties harvested during end of April to end of June were considered as Middle early (Ross and Banglora). Difference between mango varities in flowering and maturity was also observed by Jilani et al. (2010) under Pakistan conditions. Yield and yield component are a key target for mango groweres. The results presented in Table 3 indicated that there was a significant variation between mango genotypes in their response to local environmetal conditions with respect to yield components. Average fruit weight significantly varied from $200 \mathrm{~g}$ in Chambtan, Ross, Pairi, Baramasi and Alphonso varieties to $1200 \mathrm{~g}$ in Tenneru. Similar result was recorded by Chanana et al. (2005) on Alphonso and Langra under Indian conditions, while compared to our results the research result obtained by Kaur et al. (2014) with

Egypt. J. Hort. Vol. 42, No. 1 (2015) 
respect to fruit weight show inferior values. On the other hand, Jilani et al. (2010) obtained higher fruit weights for Alphonso (355.33 g) under Pakistan conditions. Neelum variety recorded the highest number of fruits (497 fruit/tree) and Baramasi was the lowest ( 77 fruit /tree). Average total yield per tree ranged from $15.4 \mathrm{~kg}$ in Baramasi to $217.3 \mathrm{~kg}$ in Banglora. The higher yield in Banglora may be attributed to its varietal nature of regular bearing habit, unlike Baramasi where the fruiting pattern for this variety is not uniform through the year and unpredictable. Only Neelum Banglora and Pairi exhibited true regular bearing habit. Ross trees were more efficient in production $\left(16 \mathrm{~kg} / \mathrm{m}^{3}\right)$, followed by Dashehari $\left(15.09 \mathrm{~kg} / \mathrm{m}^{3}\right)$. Tree yield efficiency was negatively correlated with tree canopy volume $(\mathrm{r}=-0.561, \mathrm{p} \leq 0.059)$ which a illustrates the importance of calculating tree canopy size and linkimg that to the productivity of the tree. The results showed that Safeda Mulgoa and Mulgoa outperformed other varieties regarding TSS contebt (21 and $20 \%$ TSS), an important factor for indicating of fruit quality while Tenneru fruits had the lowest values (13\% TSS). Similar results for Dashehar and Langra were reported by Kaur et al. 2014, but TSS\% was higher (26.84\%) in the case of Alphanso as compared to our result for this particular cultivar. While, Jilani et al. (2010) recorded similar results in Pakistan for most of tested cultivars in our experiment and may be this due to the simiarlity of climatic conditions favourable for mango cultivation in both regions. Given the nature of maturity as presented in Table 4, Middle early varieties group were significantly more productive $(133.8 \mathrm{~kg} /$ tree $)$ than other groups, however, Early group characterized with large fruit size $(650 \mathrm{~g} / \mathrm{fruit})$ while medium group have high quality fruits (18.9\%).

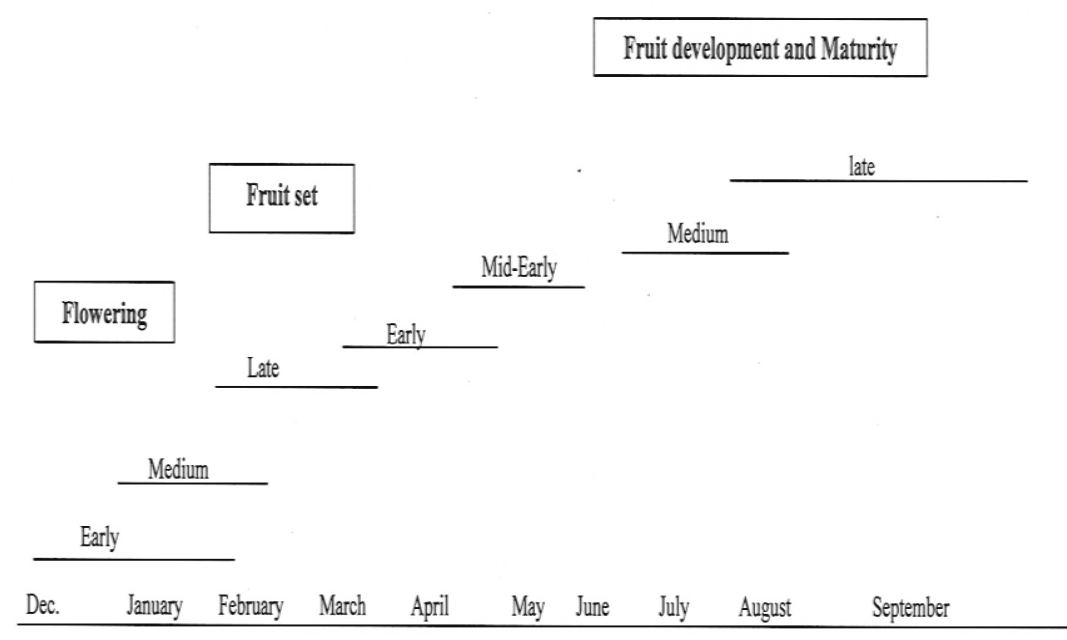

Fig. 1. Flowering, fruiting stages for mango varieties. 


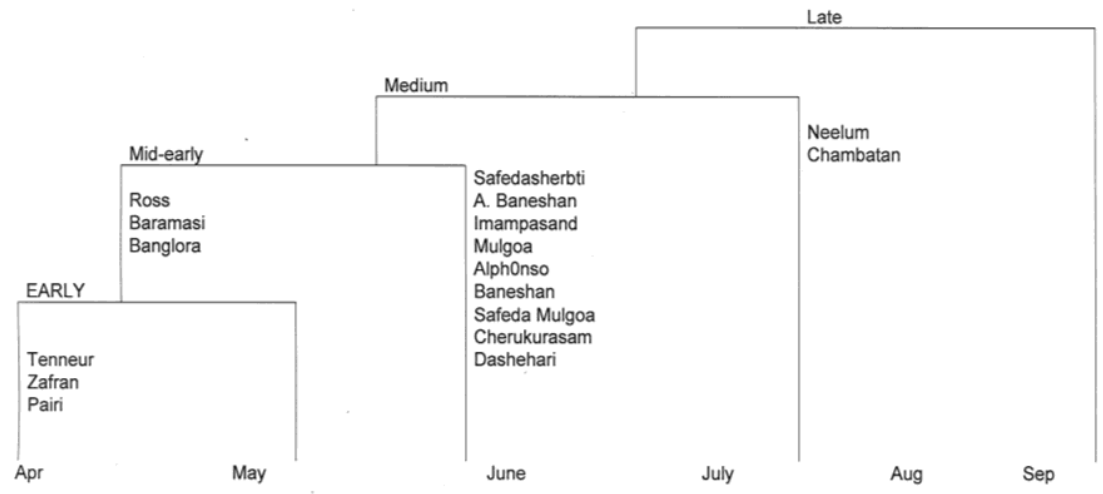

Fig. 2. Classification of mango varieties according to maturity period.

TABLE 3. Yield components of different mango varieties grown under the Sultanate of Oman conditions.

\begin{tabular}{|c|c|c|c|c|c|}
\hline Varieties & $\begin{array}{c}\text { Fruit weight } \\
\text { (g) }\end{array}$ & Fruit No./ tree & $\begin{array}{c}\text { Tree yield } \\
(\mathbf{k g})\end{array}$ & $\begin{array}{c}\text { Tree yield } \\
\text { efficiency } \\
\left(\mathrm{kg} / \mathrm{m}^{3}\right)\end{array}$ & $\begin{array}{c}\text { TSS } \\
\%\end{array}$ \\
\hline Allumpur Baneshan & 300.00 & 131.00 & 39.30 & 2.47 & 18.00 \\
\hline AlPhonso & 200.00 & 223.00 & 44.60 & 3.24 & 17.00 \\
\hline Banglora & 550.00 & 395.00 & 217.30 & 7.43 & 16.00 \\
\hline Baneshan & 450.00 & 152.00 & 68.40 & 4.54 & 19.00 \\
\hline Baramasi & 200.00 & 77.00 & 15.40 & 2.60 & 18.00 \\
\hline Cherukurasam & 316.00 & 254.00 & 80.00 & 3.82 & 18.00 \\
\hline Dashehari & 200.00 & 480.00 & 96.00 & 15.09 & 19.00 \\
\hline Imampasand & 492.00 & 90.00 & 44.00 & 0.46 & 18.00 \\
\hline Langra & 234.00 & 312.00 & 73.00 & 4.63 & 19.00 \\
\hline Mulgoa & 347.00 & 165.00 & 57.00 & 3.62 & 20.00 \\
\hline Neelum & 240.00 & 497.00 & 119.30 & 6.36 & 18.00 \\
\hline Pairi & 200.00 & 352.00 & 70.40 & 3.45 & 18.00 \\
\hline Ross & 200.00 & 251.00 & 50.20 & 16.64 & 14.00 \\
\hline Safeda Mulgoa & 450.00 & 187.00 & 84.20 & 3.38 & 21.00 \\
\hline Tenneru & 1200.00 & 93.00 & 111.60 & 1.80 & 13.00 \\
\hline Zafran & 550.00 & 153.00 & 84.20 & 1.46 & 17.00 \\
\hline Chambatan & 200.00 & 251.00 & 50.20 & 3.05 & 15.00 \\
\hline Mean & 372.29 & 239.00 & 76.77 & 4.94 & 17.53 \\
\hline $\begin{array}{c}\text { SE } \pm \\
\text { Range }\end{array}$ & $\begin{array}{c}90.80 \\
200-1200\end{array}$ & \begin{tabular}{|c|}
58.29 \\
$93.00-497.00$
\end{tabular} & \begin{tabular}{c|}
18.72 \\
$15.40-217.13$
\end{tabular} & $\begin{array}{c}1.21 \\
2.60-16.64\end{array}$ & $\begin{array}{c}4.28 \\
13-21.00\end{array}$ \\
\hline
\end{tabular}

Egypt. J. Hort. Vol. 42, No. 1 (2015) 
TABLE 4. Yield and chemical characters of mango varieties according to Maturity periods.

\begin{tabular}{|c|c|c|c|c|c|}
\hline $\begin{array}{c}\text { Ripening } \\
\text { period }\end{array}$ & $\begin{array}{c}\text { Fruit weight } \\
(\mathbf{g})\end{array}$ & $\begin{array}{c}\text { TSS } \\
\mathbf{\%}\end{array}$ & $\begin{array}{c}\text { Fruit No/ } \\
\text { tree }\end{array}$ & $\begin{array}{c}\text { Total tree } \\
\text { yield } \\
\text { Kg/tree }\end{array}$ & $\begin{array}{c}\text { Tree yield } \\
\text { efficiency } \\
\left(\mathbf{k g} / \mathbf{m}^{\mathbf{3}}\right)\end{array}$ \\
\hline Early & $650.0 \pm 292.973$ & $16.0 \pm 1.528$ & $199.3 \pm 78.274$ & $88.7 \pm 12.107$ & $2.2 \pm 0.616$ \\
\hline Mid-Early & $375.0 \pm 175.000$ & $15.0 \pm 1.000$ & $323.0 \pm 72.000$ & $133.8 \pm 83.550$ & $12.0 \pm 4.604$ \\
\hline Medium & $353.3 \pm 043.247$ & $18.9 \pm 0.508$ & $180.0 \pm 27.094$ & $58.6 \pm 6.442$ & $3.2 \pm 0.537$ \\
\hline Late & $220.0 \pm 020.000$ & $16.5 \pm 1.500$ & $374.0 \pm 123.000$ & $84.8 \pm 34.550$ & $4.7 \pm 1.655$ \\
\hline
\end{tabular}

\section{Conclusion}

The studied mango varieties varied gratly in vegetative, reproductive and fruit quality characters. Based on a wide range of maturity periods, varieties were calassified as Early, Mid-early, Medium and Late. These results will encourage the efforts of sustainability of mango cultivation in different agroclimatic conditions regions of the Sultanate. However, multilocational and onfarm variety trials are needed.

Acknowledgement: The authors would like to thank Dr. Saleem Nadaf, Plant Genetic Resources expert, Plant Production Research Centre, Ministry of Agriculture and Fisheries. Also, our thanks to Mr. Hussain Khalil Omar and Suleiman Rasheed Al-Balushi, technical assistants for their assistant in conducting this experiment and collecting the data.

\section{References}

Abutiate, W.S. (1987) Evaluation of new cultivars of mango (Mangifera indica l.) in Ghana. 1. Growth parameters. Ghana Journal of Agricultural Sciences, 20-23, 25-31.

Akhtar, S. Seema mahmood, Naz, S., Muhammad Nasir and Sault, M. T. (2009) Sensory evaluation of mangoes (Mangifera indica 1.) grown in different regions of Pakistan. Pakistan Journal of Botany, 41 (6), 2821-2829.

Chanana, Y.R., Jasam, I.S. and Arora, P.K. (2005) Evaluation of some mango cultivars under Indian conditions. Proceeding International Conference on mango and date Palm: Culture and Export. 23 - 23 June.

Jilani, M.S., Waseem, F.K., and Khan, M.A. (2010) Evaluation of physico-chemical characteristics of mango (Mangifera indica L.) Cultivars Grown in d. I. Khan. Evaluation of physico-chemical characteristics in mango. Journal of Agricultural. Research, 48 (2), 25-27.

Kaur, M., Bal, J.S., Sharma, L.K., and Bali, S.K. (2014) An Evaluation of mango (Mangifera indica L.) germplasm for future breeding programme. African Journal of Agricultural Research, 9 (20),1530-1538. 
MAF (2013) Agricultural census. Directorate General of Planning and Development. Ministry of Agriculture and Fisheries, Sultanate of Oman.

Mahabir, S. and Kanpure, R.N. (2006) Performance of mango cv. Langraon different root. International. Journal of Agricultural Sciences, 2 (2), 564-565.

Naqvi, S.A.H., Perveen, R., Manzoori, S.A., Umar, H.M.I., Iqbal, M.T., Liaquat, F., Majid, T. and Irshad, A. (2014) Evaluation of various mango varieties against the infection dy namics of powdery Mildew (Oidium mangiferae Bert.). American Journal of Plant Sciences, 5, 2372-2377.

Okoth, E.M., Sila, D.N., onyango, C.A., Owino, W.O., Musembi, S.M. and Mathooko, F.M. (2013) Evaluation of phy sical and sensory quality attributes of three mango varieties at three stages of ripeness, grown in lower eastern provinve of Keny a- part 1. Journal of Animal and Plant Sciences, 17 (3), 2608-2618.

Rajan, S., Kummar, R. and Negi, S.S. (2001) Variation in canopy characterstics of mango (Mangifera indica L.) cultivars from diverse eco-geografical regions. Journal Applied Horticulture, 3 (2), 95-97.

Singh, M. and Kanpur, R.N. (2006) Performance of mango cv. Lanra on different rootstock. International Journal Agriculture Society, 2 (2), 564-565.

Usman, I.A.M., Rashid, S. Saeed, M.K. and UI-Haq, I. (2011) Evaluation of quality of mango squashes available in Lahore market. Pakistan Journal of Food Science, $2(1-4), 67-71$.

Zekri, M. (1996) Leaf mineral concentration, growth, yield, fruit quality and economics of 'Ambersweet' oranges on two rootsocks. Proceeding of the Florida State Horticultural Society, 109, 92-96. 


\section{نمو وإنتاجية وجودة صفات اصناف الماتجو تحت ظروف سلطنة \\ عمان}

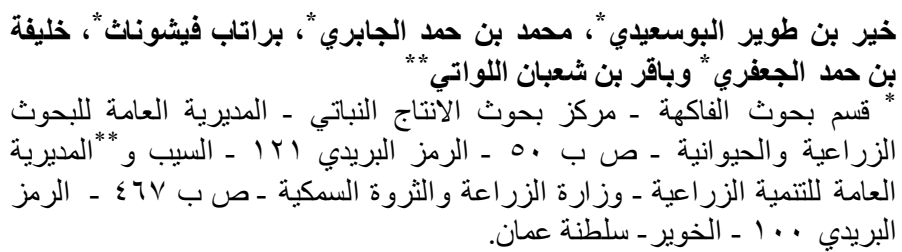

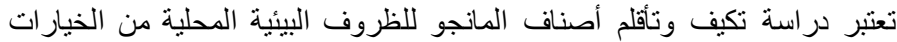

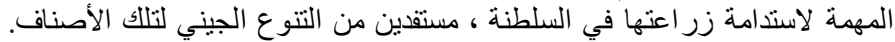

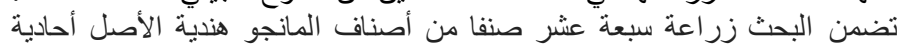

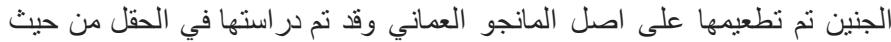

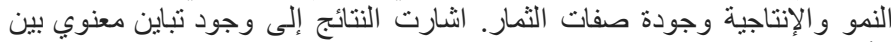

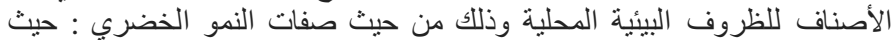

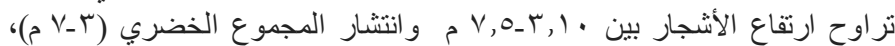

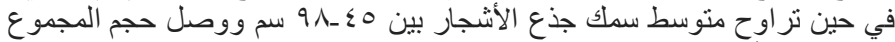

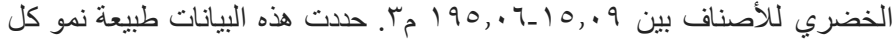

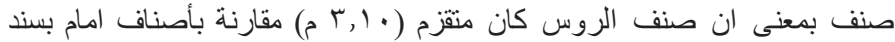

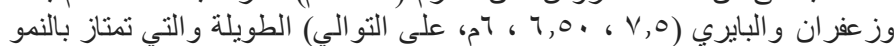

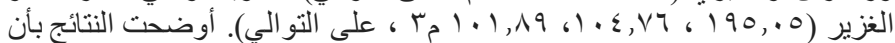

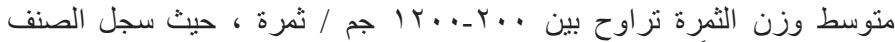

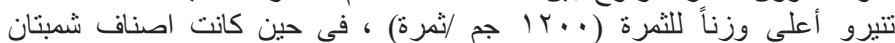

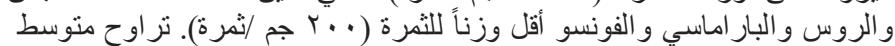

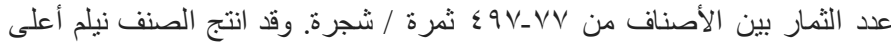

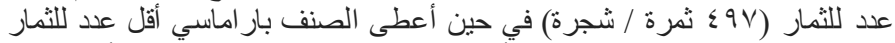

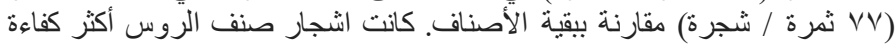

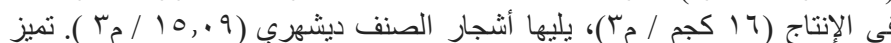

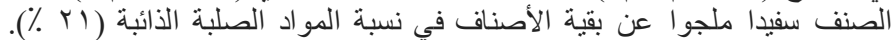

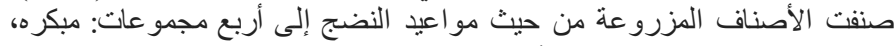

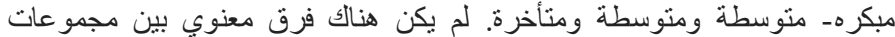

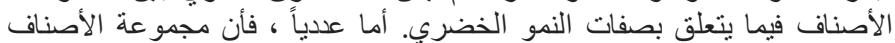

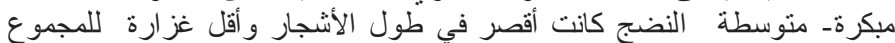

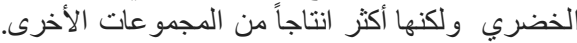

توجد علاقة سلبية بين كفاءة انتاج الثجرة وحجم مجموعها الخضري (r) (P $\mathrm{P} 0.05$ ، 0.561

خلاصة البحث تبين بأن أقلمة أصناف المانجو ذات التنوع الجيني تعثبر طريقة

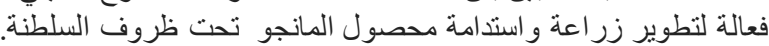

